psychiatrists. This is revealed in discussions with colleagues and published case-notes as well as in confidential files. They seem not to realise that offensive remarks show more about their attitude towards others and their inability to say within professional boundaries than about those they describe. It is a cowardly practice as insulting remarks can be trivialised, denied or the patient intimidated from making a formal complaint by professionals closing up.

Users of psychiatric services are usually in distress. There is a wide range of personalities and behaviour patterns which psychiatrists encounter and if they cannot manage without becoming offensive and insensitive, perhaps they should reconsider their coping mechanisms.

37 Monmouth House

SUSANNE STEVEnS

Raglan Street

Kentish Town

London NW5 3BX

\section{The dog did it}

\section{DeAR SirS}

A letter which a GP had written to me, referring a new patient, had been given to the patient to deliver to me. Explaining the two-month gap between the GP writing the referral and my receiving it, the patient wrote "I enclose my GP reference, and should explain the reason for the somewhat tardy submission. I had assumed that this had been posted by my wife. Unfortunately, my dog saw fit to bury the document which has only just come to light. My apologies".

There was clear evidence of water damage to the patient referral letter, so I do believe that the dog did do it. As far as explanations for the late arrival of mail, this certainly takes the (dog) biscuit.

Claybury Hospital

I. O. AzUONYE

Woodford Green

Essex IG8 8BY

\title{
Post traumatic stress disorder - a controlled study
}

A controlled study is being conducted at Professor Isaac Marks' Research Unit, The Maudsley Hospital. Patients suffering from PTSD of at least six months' duration would be offered rapid assessment for behaviour and/or cognitive therapy.
Patients can be referred to and more information obtained from Dr H. Noshirvani, The Maudsley Hospital, 99 Denmark Hill, London SE5 (telephone 071-703 6333, extension 3458). 